\title{
Huguette Krief, Entre Terreur et vertu. Et la fiction se fit politique...(1789-1800)
}

\section{Regina Bochenek-Franczakowa}

\section{(2) OpenEdition}

1 Journals

Édition électronique

URL : http://journals.openedition.org/studifrancesi/5634

DOI : 10.4000/studifrancesi.5634

ISSN : 2427-5856

Éditeur

Rosenberg \& Sellier

\section{Édition imprimée}

Date de publication : 1 septembre 2011

Pagination : 410

ISSN : 0039-2944

\section{Référence électronique}

Regina Bochenek-Franczakowa, « Huguette Krief, Entre Terreur et vertu. Et la fiction se fit politique... (1789-1800)», Studi Francesi [En ligne], 164 (LV | II) | 2011, mis en ligne le 30 novembre 2015, consulté le 08 janvier 2021. URL : http://journals.openedition.org/studifrancesi/5634 ; DOI : https://doi.org/ 10.4000/studifrancesi.5634

Ce document a été généré automatiquement le 8 janvier 2021.

\section{(c) (†) $\ominus$}

Studi Francesi è distribuita con Licenza Creative Commons Attribuzione - Non commerciale - Non opere derivate 4.0 Internazionale. 


\title{
Huguette Krief, Entre Terreur et vertu. Et la fiction se fit politique...(1789-1800)
}

\author{
Regina Bochenek-Franczakowa
}

\section{RÉFÉRENCE}

HUGUETTE KRIEF, Entre Terreur et vertu. Et la fiction se fit politique...(1789-1800), Paris, Honoré Champion, 2010, pp. 533.

1 La thèse principale qui fonde la réflexion et l'analyse contenues dans l'ouvrage, est celle de l'engagement politique de la fiction romanesque au temps de la Révolution française. L'auteure vise en premier lieu à démontrer que «les romanciers de cette période effervescente sont convaincus de l'efficacité politique et morale de leurs écrits» (p. 27) ce qui explique la perspective adoptée dans cet ouvrage. Le vaste et riche matériel est organisé autour de trois axes de pensée, qui structurent l'ensemble en trois parties: "comprendre», «régénérer» et "sentir», ayant à rendre la complexité et spécificité de la production romanesque de la décennie révolutionnaire.

«Comprendre» désigne le désir des romanciers de saisir le fil d'Ariane du labyrinthe des événements révolutionnaires, imprévisibles et mouvants. H. Krief décèle deux attitudes, l'engagement dans ou contre la cause révolutionnaire et le scepticisme, voire l'hostilité envers la Révolution. L'auteure nous fait connaître des textes fort divers, souvent inconnus-depuis des pamphlets antimonarchiques et autres récits patriotiques jusqu'aux plaidoyers royalistes de la fin du Directoire. L'attitude "sceptique», que représentent ici deux romans de Mme de Charrière et Ann' Quin bredouille de J. C. Gorjy, exprime une attitude de doute et d'inquiétude de certains esprits face aux violences de la Révolution. L'auteure a raison d'accorder au roman satirique et «carnavalesque» de Gorjy une attention particulière, c'est une œuvre étonnante, injustement méconnue, de cette décennie.

«Régénérer» concerne l'idée abstraite à laquelle la génération des révolutionnaires a voué un culte particulier. La vision de l' «homme nouveau» nourrit toute une 
littérature engagée, romans à thèse - véritables «catéchismes républicains» dont $\mathrm{H}$. Krief nous présente les exemples les plus spectaculaires. Cette production, fondée sur une sorte de prédication laïque, devait donner des modèles de renaissance politique et morale de la France. À cette littérature appartiennent aussi les récits patriotiques allégoriques, les apologues politiques, la pastorale. Cette partie de l'ouvrage contient également l'étude des romans d'apprentissage, qui proposent de nouveaux modèles d'éducation: celle des princes et celle des femmes. Cette partie de l'ouvrage contient, enfin, un chapitre fort intéressant sur la problématique féminine: des romans sentimentaux qui montrent la "femme régénérée» jusqu'aux récits pour ou contre le féminisme patriotique, l'auteure nous fait découvrir des textes où l'égalité de la femme obtient des éclairages variés.

4 La troisième partie de l'ouvrage, placée sous le signe de «sentir», renvoie au roman qui «parle au cœur» et aux sens. L'amour d'autrui, la bienfaisance, tous ces accessoires du sentimentalisme des Lumières réapparaissent dans plusieurs romans de la Révolution, à travers plaidoyers contre l'esclavage des Noirs aux colonies, représentations des réalités de la Terreur dans les romans aux couleurs sombres, tableaux émouvants de l'émigration. Mais sentir, nous fait observer à juste titre l'auteure, concerne aussi la littérature libertine qui ne disparaît pas sous la Révolution: à part la riche production de textes anticléricaux, H. Krief nous fait découvrir des textes inconnus, au statut ambigu, telle Julie philosophe (anonyme) ou Illyrine de Mme Giroust. Les romans du marquis de Sade et d'Andréa Nerciat trouvent la place qui leur revient dans cette perspective - l'auteure insiste ici sur ce qui sépare ces œuvres du contexte social et littéraire de la période.

5 En concluant son ouvrage, H. Krief relève un double mouvement dans la littérature romanesque examinée: «une ouverture sur le monde de la Régénération [...] et un repli sur la vie intérieure, celle d'esprits éprouvés par les remous de l'Histoire révolutionnaire» (p. 470). Une esquisse de l'évolution est dessinée, de la littérature engagée et optimiste d'avant 1794 à la désillusion de l'après Thermidor, mais H. Krief n'y insiste pas. Son intérêt est centré principalement sur le message véhiculé par les romans et récits de la Révolution, dans un contexte à la fois politique de l'actualité révolutionnaire et philosophique, au sens de l'attachement à la pensée des Lumières. Dans la bibliographie d'études sur le roman de la Révolution française, l'ouvrage de Huguette Krief occupe une place importante: l'auteure y dresse un tableau complet de la production romanesque de cette période, avec des informations à la fois riches et compétentes sur des auteurs et des œuvres qui, pour la plupart des cas, sont peu ou mal connus. 